\title{
Canadian urology programs can be leaders in competency-based education
}

\author{
Jason R. Frank, $M D, M A(E d)$, FRCPC \\ See related article on page 395
}

$\mathrm{n}$ this issue of CUAJ, Mickelson and MacNeily ${ }^{1}$ describe a guide for urology teachers to implement the CanMEDS competencies in the discipline. These general principles for programs are most welcome and very much in alignment with work already done by Fellows of the Royal College of Physicians and Surgeons of Canada (RCPSC). In this commentary, I will clarify contemporary thinking on competencybased education, the CanMEDS initiative and the resources available for urology teachers and educators.

\section{Competency-based education}

As alluded to in Mickelson and MacNeily's article, the CanMEDS story is part of a wider evolution of medical education worldwide. CanMEDS began in response to requests from College Fellows, including urologists, who were concerned about being prepared for practice amid the dynamic changes in medicine. Canadian training is already renowned around the globe, as attested by the prestige and portability of the FRCSC and FRCPC designations. However, in our era of accountability, consumerism, government intrusion, erosion of professional autonomy and exponential growth in science, the training of physicians has moved toward a greater focus on program outcomes and not just process. $^{2}$ In outcome-based design, the first task of educational leaders is to define the abilities needed by graduates for practice, based on the needs of those they serve and the contexts in which they will practice. ${ }^{3,4}$ Defining these abilities or comprehensive competencies is a major trend in most Western countries. ${ }^{5}$ In this way, programs are being designed with the end in mind, as opposed to the recent times when programs were solely focused on core medical knowledge and tended to be less structured. Canadian urology graduates are excellent surgeons. CanMEDS is an example of an initiative designed to ensure that this continues to be the case in the 21 st century.

\section{The RCPSC CanMEDS initiative}

The CanMEDS program has now been underway for nearly 2 decades, ${ }^{6}$ and was updated in 2005..$^{7}$ In fact, CanMEDS has influenced or has been adopted in at least 17 jurisdictions around the world. It has also been used in the frameworks of at least 8 health professions. In the UK for example, several royal colleges use CanMEDS as does the Australian Medical Council, the Dutch Central College of Medical Specialties and the College des Médecins du Québec. In the United States, the
Accreditation Council for Graduate Medical Education (ACGME)'s Marvin Dunn's visit to the RCPSC in 1997 led to the development of the ACGME's Six Competencies model. Canadian urologists have written to the RCPSC for assistance with presenting CanMEDS at international meetings. CanMEDS, developed by Canadian physicians, is hugely influential and worthy of pride.

Mickelson and MacNeily are critical of the implementation of CanMEDS, describing it as "nebulous," "poorly defined," "abstract" and with a "paucity of tools to teach them." These are among several unsubstantiated misunderstandings about CanMEDS in the article. These same criticisms have also been levelled at the ACGME competencies and others used around the world. Rather, there are 2 fundamental truths to consider about the implementation of CanMEDS in Canadian programs: 1) many of these competencies have always been taught and assessed but need to be made explicit; and 2) this competency-based approach requires each specialty to clearly define what the CanMEDS roles mean for their practice. The authors confuse the inherently generic nature of the CanMEDS competencies framework for lack of clarity. CanMEDS is a framework that must be adaptable by all the College's 62 disciplines. In fact, thanks to the hard work and dedication of Canadian physicians and surgeons, most of the RCPSC specialty committees have successfully defined specific and comprehensive standards that define what it means to be competent in their specialty using CanMEDS. These are publicly available at http://rcpsc.medical.org/information/index.php. The approximately 700 specialty programs have all been visited by peer reviewers as part of the accreditation cycle, and all have implemented CanMEDS in the programs in a variety of ways. 
Smart program directors and teachers have realized that much of CanMEDS is already present, built on the longstanding strengths of Canadian specialty training. What is needed is an effort by every specialty and every program to take stock of their teaching and assessment practices using the CanMEDSbased standards.

\section{Resources for urology educators}

Mickelson and MacNeily are indeed correct that more resources are needed to make CanMEDS and competency-based implementation as easy as possible for busy clinicians. The good news is that many resources exist to assist educators, and many more are coming. The challenge is that there is no "cook book" or "off the shelf" answer for any program, and all the tools and resources in the world cannot be a substitute for dedicated faculty and skilled teachers. The RCPSC CanMEDS team works tirelessly to support educators in their use of CanMEDS. Nearly 1000 faculty development workshops and presentations have been given since 2001. CanMEDS has distributed thousands of resource items, including pocket cards, CanMEDS books, posters and the important Assessment Tools Handbook, ${ }^{8}$ a key reference for those looking for ways to measure the competence of their residents in each domain. CanMEDS has also trained more than 100 regional "champions" for the roles of Communicator, Collaborator and Health Advocate as part of an elaborate trainthe-trainer program. Workshops on Manager, Lifelong Learning, Residents as Teachers, Resident Research, Professionalism, Physician Health and Clinical Reasoning will follow. CanMEDS has a comprehensive implementation strategy, and every school and specialty already has extensive resources to assist those interested in excellence in residency training.

The paper by Mickelson and MacNeily is a welcome addition to the existing resources. They provide an accessible series of recommendations for making the CanMEDS competencies explicit in teaching and assessment for urology. Canadian urology is filled with skilled clinicians, superb educators and leaders in medicine. By further implementing the needs-oriented, competency-based concepts of CanMEDS, Canadian urology training will continue to be world leading.

Associate Director, Office of Education, Royal College of Physicians and Surgeons of Canada, Ottawa, Ont.

Competing interests: Dr. Frank is an employee of the Royal College of Physicians and Surgeons of Canada.

\section{References}

1. Mickelson JJ, MacNeily AE. Translational education: tools for implementing the CanMEDS competencies in Canadian urology residency training. CUAJ 2008;2:395-404.

2. Harden RM, Crosby JR, Davis MH. Outcome-based education: Part 1 - an introduction to outcome-based education. Med Teach 1999;21:7-14.

3. Smith S.R., Dollase R. Planning, implementing and evaluating a competency-based curriculum. AMEE education guide no. 14 part 2. Med Teach 1999;21:15-22.

4. Aretz HT. How good is the newly graduated doctor and can we measure it? Med J Aust 2003; 178:147-8.

5. Harden RM. Developments in outcome-based education. Med Teach 2002;24:117-20.

6. Frank JR. The CanMEDS project: the RCPSC moves medical education into the $21 \mathrm{st}$ century. In: Dinsdale HB, Hurteau G, editors. The evolution of specialty medicine. Ottawo (ON): Royal College of Physicians and Surgeons of Canada; 2004.

7. Frank JR, editor. The CanMEDS 2005 physician competency framework. Ottawa (ON): Royal College of Physicians and Surgeons of Canada; 2005.

8. Bandiera G, Sherbino J, Frank JR. The CanMEDS assessment tools handbook. Ottawo (ON): The Royal College of Physicians and Surgeons of Canada; 2006.

Correspondence: Dr. Jason R. Frank, Director of Education, Department of Emergency Medicine, University of Ottawa, 774 Echo Dr., Ottawa ON KIS 5N8; jfrank@rcpsc.edu 